\title{
Contextual Influences on Breastfeeding Practices in Selected West African Countries
}

\author{
Taofik Olatunji Bankole ${ }^{1^{*}}$ \\ Bola Lukman Solanke ${ }^{2}$
}

Luqman Adeleke Bisiriyu ${ }^{3}$

\section{${ }^{2,2}$ Department of Demography and Social Statistics, Faculty of Social Sciences, Obafemi Awolowo University, Ile-Ife, Nigeria. \\ Email:oluwabamikoleolatunji@gmail.com Email:bsolanke@oanife.edu.ns \\ ${ }^{\circ}$ Emailiabisi@oauife.edu.ng \\ Licensed: \\ This work is licensed under a Creative Commons Attribution 4.0 License.}

Keywords:

Contextual

Optimal breastfeeding

Community factors

Household

West Africa.

Accepted: 3 January 2020

Published: 20 January 2020

(* Corresponding Author)

\begin{abstract}
Studies have examined the predictors of breastfeeding practices across countries in West Africa. However, these studies neither employed multilevel methodological approach nor conceptualized breastfeeding practices beyond the conventional categorisation. This study addresses this limitation by investigating contextual influence on breastfeeding practices in three selected West African countries. The study analysed data extracted from the Demographic Health Surveys in Sierra Leone (2013 SLDHS), Nigeria (2013 DHS) and Guinea (2012 GDHS. Information was extracted from a weighted sample size of 5,008 (SLDHS), 12,180 (NDHS) and 3,082 (GDHS) for fecund mothers aged 20-49 years who have had at least a child preceding the surveys. The outcome variable was breastfeeding and which was dichotomised into optimal and suboptimal breastfeeding. Optimal breastfeeding was coded into " 1 " if adhered to and " $O$ " if otherwise. The explanatory variables were the contextual factors measured as the individual, household, and community levels. The multilevel mixed-effect logistic regression was applied using Stata 14. The fixed effect results showed that breastfeeding practice was significantly associated with contextual factors $(p<0.05)$. Results of the random effects showed that community factors accounted for $38.2 \%, 18.3 \%$ and $17.3 \%$ variation in adherence to optimal breastfeeding for mothers in Guinea, Nigeria and Sierra Leone respectively. Contextual factors are key predictors of optimal breastfeeding among women of reproductive age in Guinea, Nigeria and Sierra Leone.
\end{abstract}

Funding: This study received no specific financial support.

Competing Interests: The authors declare that they have no competing interests.

Acknowledgement: The authors expresses gratitude to the National Population Commission (NPC) [Nigeria $]$, ICF International and MEASURE DHS Project for making the datasets available for use.

\section{Introduction}

The act of optimal breastfeeding probably is essential for the proper health growth, and development of the newborn. It is so much important that it promotes the healthy living of the lactating mother, particularly in the prevention of ovarian cancer (UNICEF, 2016). Thus, it may perhaps be contended that not just any act of breastfeeding but optimal breastfeeding plays a significant role in the promotion of maternal and infant health, thereby enhancing their survival. Newborns that are optimally breastfed are found to be less susceptible to physiological and cognitive impairments as they grow into adulthood. These assertions buttressed those by Arora et al. (2017) where the survival and healthy living of growing children were attributed to how much breastmilk they were fed with at the early formative stage of infanthood.

More so, denying infants of exclusive breastfeeding makes them susceptible to respiratory infections, gastro-intestinal diseases, diabetes, asthma and other related childhood infections (Ogbo, Page, Idoko, Claudio, \& Agho, 2017) Recent facts linking growing children health to breastfeeding revealed that about $43 \%$ of early childhood deaths arising majorly from respiratory infections and sudden infant-death were largely attributed to non-compliance of mothers to optimal breastfeeding practices (UNICEF, 2017). Equally, feeding newborns with colostrum, and breastfeeding infants at least exclusively for six months safeguard them against deadly 
early childhood infections that are peculiar to infants and growing children. For example, infants and young children that were alternatively fed with supplements were more susceptible to poor brain development and also at a higher risk of developing cognitive impairments (Julie, Ene-Obong, Edet, \& Udoh, 2016; Mucha, Blomberg, \& Stockdale, 2016).

However, poor infant and young child feeding was more pronounced in the sub-Saharan African region and it was argued that babies that were born in this region were ten times more likely to die from early childhood infections compared to babies that were born in developed regions (Andy, 2015; Victora et al., 2016). Thus, this buttresses the factual statement which argued that sub-Saharan Africa had the largest proportion of the global annual deaths of 2.6 million under five, majorly due to the non-adherence of mothers to the recommended breastfeeding practices (UNICEF, 2017). Timing of breastfeeding initiation among mothers was relatively delayed compared to timing in other sub-regions in Africa; consequently, many babies born in the West African region were at higher risk of dying before age five as a result of the poor feeding (Rutstein \& Rebecca, 2014; UNICEF, 2016).

In the West African region, prevalence of household poverty as well as the poor socioeconomic conditions of most women, absence of timely supports from relatives or partners negligence on the side of nursing mothers and the uncared-attitude by some healthcare workers, were amongst the leading threats that were restraining mothers from adhering to optimal breastfeeding (Andy, 2015; Hashim et al., 2017; World Health Organization, 2016). Indications from previous studies have clearly revealed that young children that were neither exclusively breastfed for a period of six months nor put to breast milk within an hour after birth were more susceptible to chronic and deadly infections than those that were optimally breastfed (Bisiriyu, Bankole, \& Solanke, 2016; Derso, Biks, Tariku, \& Tebeje, 2017; Sholaye, Badejo, \& Jeminusi, 2014). Consequently, lifelong physical and cognitive impairments in growing children have been linked to improper and suboptimal breastfeeding practices among women (Aakre et al., 2017; Victora et al., 2016). Nearly, 25 million infants and young children in the world were not exclusively breastfed (UNICEF Global Databases, 2014). Consequently, malnourished infants and young children, particularly those that were not exclusively breastfed in their first three months and three weeks of life accounted more for the approximated 2.6 million deaths of infants every year (UNICEF, 2017).

In West Africa, the non-adherence of lactating women to optimal breastfeeding practice made them more susceptible to developing ovarian cancer; while their infants or young children under the age of five were less likely to pull through if infected with chronic early childhood diseases (Amah, Ekwe, Andrew, Ezeugwu, \& Orekyeh, 2015; Diallo, Bell, Moutquin, \& Garant, 2009; Otoo, Lartey, \& Pérez-Escamilla, 2009). Rutstein and Rebecca (2014) observed a significant proportion of women in West Africa had a good knowledge of the health implications of optimal breastfeeding, yet a larger proportion of these women were not fully adhering to this recommended breastfeeding practice, majorly a result of their poor nutritional status and cultural conformity.

In spite of the numerous studies on breastfeeding practices across West Africa, three gaps are identified in literature. To begin with, contemporary studies on breastfeeding practices (Asfaw, Argaw, \& Kefene, 2015; Genetue, Yenit, \& Tariku, 2017; Tewabe et al., 2017) in the West African region, and in sub-Saharan Africa as a whole have either specifically focused attention separately on the predictors of exclusive breastfeeding (Mogre, Dery, \& Gaa, 2016; Ogbo., Page, Idoko, Claudio, \& Agho, 2017; Onah et al., 2014; Tampah-Naah \& Kumi-Kyereme, 2013) or timing of breastfeeding initiation (Engebretsen, Nankabirwa, Doherty, \& Diallo, 2014; Horii, Allman, Martin-Prével, \& Waltisperger, 2017) rather than explore the extent to which optimal breastfeeding was being practiced as recommended by the World Health Organisation.

Therefore, insignificant attention has been challenged towards exploring the implications for nonadherence optimal breastfeeding practice. Consequently, if optimal breastfeeding had been fully adhered to, this would likely have brought about a significant reduction in the annual alarming death figure of over 8 million under five children reported globally (UNICEF, 2016). Also, most existing studies are country-specific studies (Bankole \& Adetutu, 2015; Horii et al., 2017; Jakobsen, Sodemann, Biai, Nielsen, \& Aaby, 2008; Morhason-Bello, Adedokun, \& Ojengbede, 2009). Studies exploring the factors that are key to the nonadherence of mothers to optimal breastfeeding practices across countries in West Africa rarely exist within the region. This has limited the identification and understanding of the conceivable divergent factors that may be influencing the extent to which optimal breastfeeding is being adhered to by women within the sub region of West Africa.

More so, there are also no multilevel studies addressing optimal breastfeeding practices within the West African region rather contemporary studies on breastfeeding practices have mainly analysed individual factors (Genetue et al., 2017; Horii et al., 2017; Mogre et al., 2016; Ogbo. et al., 2017) as correlates of exclusive breastfeeding practice or timing of initiation of breastfeeding practices. Hence, there is a need for this multilevel study in order to explore the homogeneity on infant and young feeding issues since breastfeeding is a cultural practice that is also community-specific. This will afford us the opportunity to correct inferences, evaluate substantive interest in group effect, thereby estimating group effects simultaneously with effects of group-level predictors - which are individual, household and community level factors in relation to this study.

This study addressed these limitations by exploring contextual influence on breastfeeding practices in three West African countries - Guinea, Sierra Leone and Nigeria. Hence, Guinea, Sierra Leone and Nigeria were selected for this study because these countries have the least adherence rates to exclusive breastfeeding 
and timing of breastfeeding initiations in the most recently conducted Demographic Heath Surveys (DHS) and Multiple Indicator Cluster Surveys (MICS) within the West African region (Population Reference Bureaus (PRB), 2018; World Health Organization, 2017).

\section{Theoretical Focus: Socio-Ecological Theory}

This study is underpinned by the Socio-Ecological theory. The idea of the Socio-Ecological theory is centered on the influence of environmental factors on human behaviour and with the aim of identifying environmental interventions. The willingness and the extent to which optimal breastfeeding is practiced as recommended by the UNICEF and WHO within the West African region is largely dependent on the demographics, socioeconomic and the cultural background of women in the region (UNICEF, 2014). Although, there may be disparities across nations within the region, there is a convergent when it comes to community approach to health related issues. This study investigates contextual influence on breastfeeding practices among fecund mothers in selected West African countries - Guinea, Nigeria and Sierra Leone. The socioecological model gives an insight to a theoretical approach to relate cultural and socioeconomic and demographic factors as correlates of breastfeeding practices at the community level, not disregarding the influence of organisational factors and government policy on the act. The theorists (McLeroy, Bibeau, Steckler, \& Glanz, 1988) maintained that health related issues are best achieved where all these five multifaceted are considered important in the formulation of approaches to promote health related programmes in the community. In line with the methodology framework of this study, the community factors, organisational factors and public policy aspects of the socioecological theory were focused on. Imperatively, no man lives in isolation nor is any man whose behaviour cannot be shaped by the influence of his community of resident. The extent to which optimal breastfeeding practice will be adhered to largely depend on how much dedicated the government of a country is prepared to implement the "Innocenti Declaration" in 1990. The term breastfeeding is a way of life in the West African region. The socioecological theory is suitable for a multilevel study; it connectively and sufficiently explained the contextual influence on breastfeeding practices. Hence, the findings from this study are in line with the assertions of socio-ecological theory as propounded by McLeroy et al. (1988).

\section{Data and Methods}

3.1. Research Design, Data Sources and Sample Size

The cross-sectional descriptive design was adopted in this study, while secondary data was employed. Thus, secondary data were extracted from the 2013 Sierra Leone Demographic and Health Survey (SLDHS), the 2013 Nigeria Demographic and Health Survey (NDHS) and the 2012 Guinea Demographic and Health Survey (GDHS). The study analysed responses from 12,180 (Nigeria), 5,008 (Sierra Leone) and 3,082 (Guinea) women of reproductive age (20-49 years) who have had at least a live birth in the last five years prior the surveys. Women who were currently pregnant, as well as women who gave birth at least two months prior the surveys were dropped from the study. This study was designed to investigate the interactional effects of individual-level, factors household factors and community-level factors on breastfeeding practices.

\subsection{Research Variables}

The outcome variable of the study is breastfeeding practice. It was captured by optimal and sub-optimal breastfeeding. The breastfeeding patterns was classified into exclusive breastfeeding, time of breastfeeding initiation, partial breastfeeding and complementary breastfeeding. The breastfeeding duration indicator was categorized into " 1 " if $<6$ months, " 2 " if $\geq 6$ months $\leq 23$ months (minimum duration of breastfeeding as recommended by UNICEF/WHO) and " 3 " if $\geq 24$ months (acceptable duration of breastfeeding as recommended by UNICEF/WHO). Exclusive breastfeeding was generated from the collapsing of timing of introduction of pre-lacteal foods and breastfeeding duration with reference to breastfeeding duration $\geq 6$ months $\leq 23$. Breastfeeding practices was categorised into two: if a child was exclusively breastfed for 6 months, breastfed for $>6$ months $\leq 23$ months and put to breastmilk immediately after birth $(<1$ hour $)$, it was captured as optimal breastfeeding and it was categorised as " 1 " or " 0 " otherwise.

The explanatory variables for this study were contextual factors. The explanatory variables were classified at the individual-level, household-level, and community-level factors making reference to noticeable important features at each of these levels of classification. The individual level variables in this study include: maternal age, maternal education, maternal occupation, marital status, maternal nutrition, body mass index, maternal employment status, parity and religious affiliation. The selected community-level variables in this study include: place of residence, community level of education, community level of poverty, community level of media saturation, community antenatal care and community hospital delivery. All variables at community level were generated from individual-level, household-level and health related variables except for place of residence and media saturation. Using Stata software, individual-level, household-level and health related variables were aggregated at the level of primary sampling unit to create the community-level variables of interest. The decision to generate the community variables of interest in this study was based on the empirical arguments from literature that breastfeeding is a cultural practice that is community specific and has been 
linked to have homogeneity influence on child bearing issues (Horii et al., 2017; Sika-Bright, 2010). The household-level factors include household headship, marriage type, spouse's level of education and household wealth index. The selection of all included explanatory variables in this study was guided by reviewed literature and by the theoretical framework established from reviewed literature. Empirically, the selected explanatory variables in this study, at the individual and community levels, are those known to have effect on breastfeeding practices as recognised and affirmatively established in the literature (Horii et al., 2017; Ogunlesi, 2010; Onah et al., 2014; Victora et al., 2016).

\subsection{Data Analysis}

Statistical analyses were carried out at the three level of analysis using Stata version 14. The response variable (breastfeeding practices) was dichotomised into " 1 " if optimal breastfeeding was practiced by mother and " 0 " if otherwise (suboptimal breastfeeding was practiced). Multilevel mixed-logistic regression was employed to examine the factors (individual, household and community factors) at two levels to the response variable. Two effects were measured. The fixed effect, where the "ordinal ratio of binary logistic regression were derived and the "random effect" where the intra-class correlation coefficients (ICC) and the log-likelihood tests were derived. All the indicators of interest in the study are well captured by the three DHS datasets employed in this study. The justification for use of multilevel analysis was the need to account for clustering in the sample design. A two-level model is specified as follows:

$$
y_{i j}=\beta_{0} X_{0 i j}+\beta_{1} X_{1 i j}+U_{j} X_{0 i j}+\xi_{i j}
$$

Where

$y_{i j}$ was breastfeeding practice of $i$ th woman in the $j$ th community.

$\beta_{0}, \beta_{1}$ were the fixed effects; $\mathrm{U}_{j}, \xi_{i j}$ were the random effects.

Three (3) models were fitted using the Stata xtmelogit command (StataCorp, 2015). In order to derive for mixed effects logistic regression, an empty model was fitted to show the magnitude of variation in the response variable (breastfeeding practice) without the covariates. Subsequent models with the inclusion of the explanatory variables were then fixed. Model 1 was fitted based on the individual-level factors. Model 2 was fitted based on household factors while Model 3 was fitted based on the community-level. The Variance Inflation Factor (VIF) was also run to check the degree of multi-collinearity of each of explanatory and intervening variables against another in the regression model. Variables with VIF $>10$ were dropped from multivariate models. This was based on the assumption that any variable with VIF $>10$ was such with a high or severe level of multi-collinearity (Akinwande, Dikko, \& Samson, 2015; O'brien, 2007). Also, the ICC was calculated as follows:

$$
\frac{\sigma_{\mathrm{ui}}{ }^{2}}{\sigma_{\mathrm{ui}}{ }^{2}+\left[\mathrm{n}^{2} / 3\right]}
$$

Where $\sigma_{\mathrm{ui}}{ }^{2}$ was the variance at the community level (Merlo, Wagner, Ghith, \& Leckie, 2016).

\section{Results}

Table 1 presents results of the likelihood of optimal breastfeeding and individual characteristics controlling for community level characteristics and household factors. Results showed that in Guinea, mothers in age $30-39$ years were $21.7 \%$ less likely to practice optimal breastfeeding than mothers in age group $20-$ 29 years $(\mathrm{OR}=0.22$; CI: $-0.19-0.62)$. Results showed that mothers in the same age group in Nigeria were $27.5 \%$ less likely to practice optimal breastfeeding practice than mothers in age group 2029 years $(\mathrm{OR}=-$ 0.28; CI: -0.43 - -0.12). In Sierra Leone, mothers in age group $40-49$ years were $39.7 \%$ less likely to adhere to optimal breastfeeding than mothers in age group $20-29$ years (OR $=-0.40$; CI: $-1.57-0.22$ ). Results further showed that there was an inverse and significant association between age and optimal breastfeeding practice in Nigeria and Sierra Leone $(\mathrm{p}<0.05)$ but differed among mothers in Guinea $(\mathrm{p}>0.05)$.

Currently married mothers in Guinea were $57.5 \%$ more likely to practice optimal breastfeeding than women that were never married $(\mathrm{OR}=1.58$; CI: $0.06-3.09)$. Results showed that currently married mothers in Nigeria were $48.2 \%$ less likely to practice optimal breastfeeding than women that were never married in the country $(\mathrm{OR}=0.48$; $\mathrm{CI}:-0.20-1.17)$, while previously married women were $8.1 \%$ less likely to practice optimal breastfeeding than never married mothers in Sierra Leone (OR = -0.56; CI: -0.21 - 0.72). Unlike in Nigeria, the results showed that marital status and optimal breastfeeding practice were significantly associated in Guinea and Sierra Leone respectively $(\mathrm{p}<0.05)$. The results further showed that type of occupation and optimal breastfeeding were significantly associated among mothers in Nigeria and Sierra Leone $(p<0.05)$ but with a contrary relationship among mothers in Guinea $(\mathrm{p}>0.05)$. The results also established the existence of significant relationship between religion and optimal breastfeeding practice in Nigeria $(\mathrm{p}<0.05)$. The odds ratio results showed that in Guinea, mothers that adequately consumed micronutrients were $65.3 \%$ less likely to practice optimal breastfeeding than mothers who never took micronutrients during gestation or lactating period $(\mathrm{OR}=0.65 ; \mathrm{CI}:-0.26-1.56)$. In Sierra Leone, mothers with inadequate consumption of micronutrients 
were $4.2 \%$ less likely to adhere to optimal breastfeeding practice than mothers with no access to micronutrients $(\mathrm{OR}=0.04 ; \mathrm{CI}:-0.45-0.36)$. In Nigeria, mothers with adequate consumption of micronutrients were $1.1 \%$ less likely to practice optimal breastfeeding than mothers who never took micronutrient supplements during the same periods (OR =-0.01; CI: -0.18-0.16). More so, results showed that mothers with normal body weight in Guinea were $38.8 \%$ less likely to practice optimal breastfeeding than underweight mothers $(\mathrm{OR}=0.39$; $\mathrm{CI}$ : $-0.70-1.48)$. In Nigeria, overweight mothers were $6.5 \%$ less likely to adhere to optimal breastfeeding practice than underweight women $(\mathrm{OR}=0.07$; CI: $-0.23-0.36)$ while in Sierra Leone, mothers with normal body weight were $7.7 \%$ less likely to practice optimal breastfeeding than underweight mothers $(\mathrm{OR}=-0.08$; CI: $-0.62-0.46)$. Also, results showed that unemployed mothers in Guinea were $22.3 \%$ less likely to practice optimal breastfeeding than gainfully employed mothers (OR $=0.22$; CI: -0.24 - 0.68). In Nigeria, unemployed mothers were $24.1 \%$ less likely to adhere to optimal breastfeeding practice than gainfully employed mothers $(\mathrm{OR}=0.24 ; \mathrm{CI}$ : $0.07-0.41)$. In Sierra Leone, gainfully employed mothers were $17.2 \%$ less likely to practice optimal breastfeeding than unemployed mothers $(\mathrm{OR}=-0.17$; CI: $-0.44-$ 0.10). Results further showed the existence of a significant association between employment status and optimal breastfeeding practice among mothers in Nigeria $(\mathrm{p}<0.05)$.

Table 2 presents results the likelihood of optimal breastfeeding and household factors controlling for individual level and community level factors. The odds ratio results showed that women whose husband had secondary school education in Guinea $(\mathrm{OR}=-0.18$; CI: $-0.89-0.54)$ and Nigeria $(\mathrm{OR}=-0.14$; CI: $-0.05-0.33)$ were $17.7 \%$ and $14.3 \%$ less likely to practice optimal breastfeeding than women whose husbands had no formal education. In Sierra Leone, results showed women with partners with only secondary school education were $28.7 \%$ less likely to practice optimal breastfeeding than those whose husbands had no formal education $(\mathrm{OR}=$ -0.29; CI: -0.55 - -0.02). The results further showed that there was an inverse and significant relationship between spouse level of education and optimal breastfeeding practice among mothers in Nigeria $(p<0.05)$. Results by marriage type showed that mothers in Sierra Leone from polygamous marriage were 9.6\% less likely to practice optimal breastfeeding than mothers in monogamous marriage (OR = -0.09; CI: $-0.12-0.31)$. In Nigeria, mothers from monogamous marriage were $2.8 \%$ less likely to adhere to optimal breastfeeding than mothers in polygamous relationship (OR = -0.03; CI: -0.21 - 0.16). Results showed that mothers from richest household in Guinea, Nigeria and Sierra Leone were $54.3 \%$ (OR = -0.54; CI: $-1.43-0.34), 22.2 \%(\mathrm{OR}=0.22$; CI: $-0.08-0.52)$ and $82.8 \%(\mathrm{OR}=-0.83$; CI: $-1.22--0.44)$ less likely to practice optimal breastfeeding than mothers from the poorest households. Results further showed the existence of a direct and significant association between household wealth and optimal breastfeeding practice in Nigeria $(\mathrm{p}<0.05)$ while there was an inverse and significant association between household wealth and optimal breastfeeding practice among mothers in Sierra Leone $(\mathrm{p}<0.05)$. Results by household heads showed that in Guinea, mothers from female headed households were $16.0 \%$ less likely to practice optimal breastfeeding than mothers from male headed households $(\mathrm{OR}=-0.16$; CI: $-0.80-0.48)$. Similarly, results showed that mothers from female headed households in Nigeria (OR = -0.09; CI: -0.34- 0.16) and Sierra Leone (OR = -0.09; CI: -0.32 - 0.15) were 8.9\% and $8.6 \%$ less likely to practice optimal breastfeeding than women from male headed households.

Table 3 presents results of the likelihood of optimal breastfeeding and community-level characteristics controlling for individual-level characteristics and household factors. The odds ratio results showed that rural resident mothers in Guinea, Nigeria and Sierra Leone were 17.0\% (OR = 0.17; CI: $-0.35-0.69), 30.0 \%(\mathrm{OR}=$ 0.30 ; CI: $-0.48--0.13)$ and $58.9 \%(\mathrm{OR}=0.59$; CI: $0.32-0.86)$ less likely to practice optimal breastfeeding than urban resident women. Also, the results further showed that place of residence and optimal breastfeeding were significantly associated $(\mathrm{p}<0.05)$. Results by community poverty concentration showed that in Guinea, mothers in the high poverty class were $20.4 \%(\mathrm{OR}=0.204$; $\mathrm{CI}$ : $0.35-0.76)$ less likely to practice optimal breastfeeding than mothers in the low poverty class. Results further showed that mothers in the high poverty class in Nigeria and Sierra Leone were $33.1 \%(\mathrm{OR}=0.331$; CI: $0.09-0.57)$ and $43.6 \%(\mathrm{OR}=-0.44$; CI: -0.75 - o.12) less likely to adhere to optimal breastfeeding than mothers in these countries. Contrarily to what was obtainable in Guinea ( $>>0.05)$, the results showed an existence of a direct and significant association between community poverty concentration and optimal breastfeeding practice among mothers in Nigeria and Sierra Leone $(\mathrm{p}<0.05)$. Results by community level of health utilisation showed that mothers with high level of health facilities utilisation during child delivery in Guinea, Nigeria and Sierra Leone were 42.7\% $(\mathrm{OR}=0.427$; CI:-0.17- 1.02), 7.4\% (OR = 0.07; CI: $-0.18-0.33)$ and 52\% (OR = 0.52; CI: $-0.84--0.19)$ were less likely to practice optimal breastfeeding than mothers with low level utilisation of healthcare facilities. Also, it was evident that community level of health facilities utilisation and optimal breastfeeding were significantly associated among mothers in the three countries $(\mathrm{p}<0.05)$. the odds results by antenatal care visits showed that mothers in Guinea, Nigeria and Sierra Leone that visited healthcare facilities at least 4 times during pregnancy were $51.1 \%(\mathrm{OR}=0.51$; CI: $-0.09-1.11), 24.2 \%(\mathrm{OR}=0.24$; $\mathrm{CI}:-0.04-0.53)$ and $17.0 \%(\mathrm{OR}=$ 0.17 ; CI: $-0.21-0.55)$ were less likely to practice optimal breastfeeding practice than mothers with low level of antenatal care visits. Furthermore, the results showed antenatal care visits and optimal breastfeeding were significantly associated among mothers in Guinea $(\mathrm{p}<0.05)$. Results by community level of media saturation showed that mothers in the community with high level of media saturation in Guinea $(\mathrm{OR}=0.142$; CI: -0.69 $0.71)$, Nigeria $(\mathrm{OR}=0.12$; CI: $-0.12-0.36)$ and Sierra Leone $(\mathrm{OR}=-0.21$; CI: $-0.54-0.11)$ were $14.2 \%, 11.6 \%$ and $32.1 \%$ less likely to practice optimal breastfeeding. 
Table 4 presents the results of the empty model for the random effects of contextual factors on adherence to optimal breastfeeding practices among mothers in Guinea, Nigeria and Sierra Leone. Hence, as presented in Table 5 the results in the "Empty Model" for Guinea, the community-level characteristics accounted for $40.4 \%$ of the variation in adherence to optimal breastfeeding practice for mothers. Likewise, in "Empty Model" for Nigeria and Sierra Leone, the community-level characteristics accounted for $20.3 \%$ and $21.4 \%$ of the variation in adherence to optimal breastfeeding practices for mothers in these two countries respectively. Also, the loglikelihood test with unpredictable values of the chi-square statistic confirmed the goodness of fit for all the fitted models $(\mathrm{p}<0.05)$.

Table-1. Binary logistic odds ratio for fixed effects related to optimal breastfeeding practices among mothers in selected West African Countries controlling for community-level characteristics and child/household factors.

\begin{tabular}{|c|c|c|c|c|c|c|c|}
\hline \multirow{2}{*}{$\begin{array}{l}\text { Characteristics } \\
\text { Age of Respondents }\end{array}$} & \multicolumn{2}{|c|}{ Guinea } & \multicolumn{2}{|c|}{ Nigeria } & \multicolumn{3}{|c|}{ Sierra Leone } \\
\hline & Coefficient & $95 \% \mathrm{CI}$ & Coefficient & $95 \% \mathrm{CI}$ & Coefficient & \multicolumn{2}{|c|}{$95 \% \mathrm{CI}$} \\
\hline $20-29$ years ref & 1.000 & & 1.000 & & 1.000 & & \\
\hline $30-39$ years & 0.217 & $-0.19 \quad 0.62$ & $-0.275^{* *}$ & $-0.43-0.12$ & -0.187 & -0.38 & -0.01 \\
\hline $40-49$ years & -0.678 & $-1.57 \quad 0.22$ & $-0.752^{* * * *}$ & $-1.02 \quad-0.49$ & $-0.397 *$ & -1.57 & 0.22 \\
\hline \multicolumn{8}{|l|}{ Educational level } \\
\hline No formal education ref & 1.000 & & 1.000 & & 1.000 & & \\
\hline Primary & 0.070 & $-0.51 \quad 0.65$ & 0.057 & $-0.14 \quad 0.26$ & -0.083 & -0.36 & 0.19 \\
\hline Secondary & -0.567 & $-1.30 \quad 0.17$ & 0.006 & $-0.21 \quad 0.23$ & -0.164 & -0.46 & 0.13 \\
\hline Post-secondary & -0.174 & $-1.79 \quad 1.44$ & -0.013 & $-0.31 \quad 0.29$ & -0.768 & -1.70 & 0.16 \\
\hline \multicolumn{8}{|l|}{ Marital status ref } \\
\hline Never married & 1.000 & & 1.000 & & 1.000 & & \\
\hline Currently married & $1.575^{*}$ & $0.06 \quad 3.09$ & 0.482 & $-0.20 \quad 1.17$ & $0.449^{*}$ & 0.04 & 0.86 \\
\hline Previously married & 0.316 & $-1.77 \quad 2.42$ & -0.143 & $-0.95 \quad 0.66$ & 0.081 & -0.56 & 0.72 \\
\hline \multicolumn{8}{|l|}{ Type of occupation } \\
\hline Not working ref & 1.000 & & 1.000 & & 1.000 & & \\
\hline Formal employment & 0.023 & $-0.54 \quad 0.58$ & $-0.233^{*} *$ & $-0.41-0.06$ & -0.309 & -0.93 & 0.31 \\
\hline Agriculture & -0.420 & $-0.94 \quad 0.09$ & -0.266 & $-0.54 \quad 0.06$ & $0.346^{*}$ & 0.06 & 0.63 \\
\hline Manual & -0.699 & $-0.22 \quad 0.77$ & -1.091 & $-2.30 \quad 0.12$ & -0.142 & -0.46 & 0.18 \\
\hline \multicolumn{8}{|l|}{ Religion ref } \\
\hline Christianity & 1.000 & & 1.000 & & 1.000 & & \\
\hline Islam & -0.214 & $-1.22 \quad 0.79$ & $0.308 * *$ & $0.14 \quad 0.48$ & 0.176 & -0.10 & 0.45 \\
\hline Traditional/Other & -1.021 & $-2.78 \quad 0.74$ & -0.338 & $-1.22 \quad 0.54$ & 0.408 & -0.62 & 1.44 \\
\hline \multicolumn{8}{|l|}{ Micronutrient intake } \\
\hline None ref & 1.000 & & 1.000 & & 1.000 & & \\
\hline Inadequate & 0.239 & $-0.19 \quad 0.67$ & -0.011 & $-0.18 \quad 0.16$ & -0.042 & -0.45 & 0.36 \\
\hline Adequate & 0.653 & $-0.26 \quad 1.56$ & -0.289 & $-0.64 \quad 0.06$ & -0.316 & -0.75 & 0.12 \\
\hline \multicolumn{8}{|l|}{ Body mass index } \\
\hline Underweight ref & 1.000 & & 1.000 & & 1.000 & & \\
\hline Normal & 0.388 & $-0.70 \quad 1.48$ & 0.067 & $-0.21 \quad 0.34$ & 0.068 & -0.37 & 0.51 \\
\hline Overweight & -0.572 & $-1.89 \quad 0.75$ & 0.065 & $-0.23 \quad 0.36$ & -0.077 & -0.62 & 0.46 \\
\hline \multicolumn{8}{|l|}{ Employment status } \\
\hline Employed ref & 1.000 & & 1.000 & & 1.000 & & \\
\hline Unemployed & 0.223 & $-0.24 \quad 0.68$ & $0.241 * *$ & $0.07 \quad 0.41$ & -0.172 & -0.44 & 0.10 \\
\hline \multicolumn{8}{|l|}{ Parity } \\
\hline$<3$ children ref & 1.000 & & 1.000 & & 1.000 & & \\
\hline$\geq 3$ children & 0.397 & $-0.48 \quad 1.27$ & -0.016 & -0.310 .28 & -0.313 & -0.80 & 0.17 \\
\hline
\end{tabular}

Table 5 presents results of the random effect of the study. Results for Guinea, the community-level characteristics accounted for $40.4 \%$ variation in adherence to optimal breastfeeding practice for mothers in Model 1, while it accounted for $38.2 \%$ and $40.3 \%$ variation in adherence to optimal breastfeeding practice in Models 2 and 3. Correspondingly, the community-level characteristics were key predictors in Nigeria - the community characteristics accounted for $20.3 \%, 18.3 \%$ and $22.7 \%$ variation in adherence to optimal breastfeeding practice for mothers in Models 1, 2 and 3. Equally, the community-level characteristics were important predictors that accounted for $20.7 \%, 17.3 \%$ and $20.7 \%$ variation in adherence to optimal breastfeeding practice for mothers in Sierra Leone, as presented in Models 1,2 and 3 respectively. Additionally, in all the selected three countries for the study, the log-likelihood test with varying figures of the chi-square statistic established the goodness of fit of Models 1,2 and $3(\mathrm{p}<0.05)$. Relatively, the community-level characteristics as presented in Table 2 were important predictors related to adherence to optimal breastfeeding practice for mothers in the three selected countries.

Figure 1 presents the results by patterns of breastfeeding practices among the respondents. The results showed that two-thirds (66.5\%) of mothers from Sierra Leone, 59.2\% and $61.3 \%$ of mothers from Guinea and 
Nigeria breastfed their babies for a duration less than 6 months. The results by time of initiation of breastfeeding showed that early initiation of breastfeeding was adhered to by more than half $(53.7 \%)$ of the respondents from Sierra Leone. contrarily, about two-thirds (64.9\%) of the respondents from Nigeria and majority $(81.6 \%)$ of the respondents from Guinea failed to initiate breastfeeding within an hour after giving birth. More so, results showed that exclusive breastfeeding was only adhered to by $30.6 \%, 24.6 \%$ and $23.5 \%$ of the respondents by mothers from Guinea, Nigeria and Sierra Leone. This is an indication that the practice of exclusive breastfeeding was relatively low among mothers across these three countries. The results also showed that optimal breastfeeding was rarely practised by most mothers in Guinea (5.3\%), Nigeria (8.6\%) and Sierra Leone $(14 \%)$. Therefore, at least 4 in every five of mothers in the three countries did not adhere to optimal breastfeeding.

Table-2. Binary logistic odds ratio for fixed effects related to optimal breastfeeding practices among mothers in selected West African Countries controlling for community-level and individual-level characteristics.

\begin{tabular}{|c|c|c|c|c|c|c|c|}
\hline \multirow[b]{2}{*}{ Characteristics } & \multicolumn{2}{|c|}{ Guinea } & \multicolumn{2}{|c|}{ Nigeria } & \multicolumn{3}{|c|}{ Sierra Leone } \\
\hline & Coefficient & $95 \%$ CI & Coefficient & $95 \% \mathrm{CI}$ & Coefficient & \multicolumn{2}{|c|}{$95 \%$ CI } \\
\hline \multicolumn{8}{|l|}{ Spouse's education level } \\
\hline No formal education ref & 1.000 & & 1.000 & & 1.000 & & \\
\hline Primary & -0.751 & $-1.52 \quad 0.02$ & 0.188 & $-0.04 \quad 0.42$ & -0.060 & -0.43 & 0.31 \\
\hline Secondary & -0.177 & $-0.89 \quad 0.54$ & 0.143 & $-0.05 \quad 0.33$ & $-0.287^{*}$ & -0.55 & -0.02 \\
\hline Post-secondary & -0.047 & $-0.98 \quad 0.89$ & 0.256 & $-0.01 \quad 0.52$ & $-0.715^{* *}$ & -1.23 & -0.21 \\
\hline \multicolumn{8}{|l|}{ Marriage type } \\
\hline Monogamy ref & 1.000 & & 1.000 & & 1.000 & & \\
\hline Polygamy & -0.001 & $-0.31 \quad 0.31$ & -0.028 & -0.210 .16 & 0.096 & -0.12 & 0.31 \\
\hline \multicolumn{8}{|l|}{ Household wealth } \\
\hline Poorestref & 1.000 & & 1.000 & & 1.000 & & \\
\hline Poorer & -0.033 & $-0.67 \quad 0.61$ & 0.260 & $-0.01 \quad 0.54$ & -0.092 & -0.36 & 0.17 \\
\hline Middle & -0.131 & $-0.72 \quad 0.46$ & $0.319^{*}$ & $0.03 \quad 0.61$ & $-0.114^{*} *$ & -0.44 & 0.22 \\
\hline Richer & 0.141 & $-0.39 \quad 0.67$ & $0.410^{*} *$ & $\begin{array}{ll}0.11 & 0.71 \\
\end{array}$ & -0.462 *** & -0.78 & -0.14 \\
\hline Richest & -0.543 & $-1.43 \quad 0.34$ & 0.222 & $-0.08 \quad 0.52$ & -0.828 & -1.22 & -0.44 \\
\hline \multicolumn{8}{|l|}{ Household head } \\
\hline Male ref & 1.000 & & 1.000 & & 1.000 & & \\
\hline Female & -0.160 & $-0.80 \quad 0.48$ & -0.089 & $-0.34 \quad 0.16$ & -0.086 & -0.32 & 0.15 \\
\hline
\end{tabular}

Notes: ${ }^{*} \mathrm{p}<0.05,{ }^{* *} \mathrm{p}<0.01,{ }^{* * *} \mathrm{p}<0.001, \mathrm{p}>0.05$ (not significant).

Table-3. Binary logistic odds ratio for fixed effects related to optimal breastfeeding practices among mothers in selected West African Countries controlling for individual-level characteristics and household factors.

\begin{tabular}{|c|c|c|c|c|c|c|c|}
\hline \multirow{3}{*}{$\begin{array}{l}\text { Characteristics } \\
\text { Community type }\end{array}$} & \multicolumn{2}{|c|}{ Guinea } & \multicolumn{2}{|c|}{ Nigeria } & \multicolumn{3}{|c|}{ Sierra Leone } \\
\hline & \multirow[t]{2}{*}{ Coefficient } & $95 \% \mathrm{CI}$ & \multirow[t]{2}{*}{ Coefficient } & $95 \% \mathrm{CI}$ & \multirow[t]{2}{*}{ Coefficient } & \multicolumn{2}{|c|}{$95 \% \mathrm{CI}$} \\
\hline & & & & & & & \\
\hline Urban ref & 1.000 & & 1.000 & & 1.000 & & \\
\hline Rural & 0.170 & $-0.35 \quad 0.69$ & $-0.300^{* *}$ & $-0.48-0.13$ & $0.589^{* * * *}$ & 0.32 & 0.86 \\
\hline \multicolumn{8}{|c|}{ Community level of poverty concentration } \\
\hline Low ref & 1.000 & & 1.000 & & 1.000 & & \\
\hline Medium & -0.340 & $-0.93 \quad 0.25$ & 0.217 & $-0.03 \quad 0.47$ & -0.009 & -0.33 & 0.32 \\
\hline High & 0.204 & $0.35 \quad 0.76$ & $0.449^{* * * *}$ & $0.21 \quad 0.69$ & $-0.487 * *$ & -0.83 & -0.14 \\
\hline \multicolumn{8}{|c|}{ Community level of women education } \\
\hline Low ref & 1.000 & & 1.000 & & 1.000 & & \\
\hline Medium & 0.194 & $-0.40 \quad 0.79$ & 0.136 & -0.110 .38 & 0.115 & -0.21 & 0.44 \\
\hline High & 0.315 & $-0.28 \quad 0.91$ & 0.331 *** & $0.09 \quad 0.57$ & $-0.436^{* *}$ & -0.75 & -0.12 \\
\hline \multicolumn{8}{|c|}{ Community level of women who delivered their babies in health facilities } \\
\hline Low ref & 1.000 & & 1.000 & & 1.000 & & \\
\hline Medium & 0.262 & $-0.35 \quad 0.87$ & 0.032 & $-0.24 \quad 0.30$ & $-0.633^{* * * *}$ & -0.97 & -0.30 \\
\hline High & 0.427 & $-0.17 \quad 1.02$ & 0.074 & $-0.18 \quad 0.33$ & $-0.520^{*} *$ & -0.84 & -0.19 \\
\hline \multicolumn{8}{|c|}{ Community level of antenatal care visit } \\
\hline Low ref & 1.000 & & 1.000 & & 1.000 & & \\
\hline Medium & $0.653^{*}$ & $0.07 \quad 1.23$ & 0.067 & $-0.22 \quad 0.36$ & 0.203 & -0.19 & 0.59 \\
\hline High & 0.511 & $-0.09 \quad 1.11$ & 0.242 & $-0.04 \quad 0.53$ & 0.170 & -0.21 & 0.55 \\
\hline \multicolumn{8}{|c|}{ Community level of media saturation } \\
\hline Low ref & 1.000 & & 1.000 & & 1.000 & & \\
\hline Medium & -0.065 & $-0.69 \quad 0.56$ & -0.095 & $-0.34 \quad 0.15$ & -0.321 & -0.65 & 0.12 \\
\hline High & 0.142 & $-0.43 \quad 0.71$ & 0.116 & $-0.12 \quad 0.36$ & -0.212 & -0.54 & 0.11 \\
\hline
\end{tabular}


Table-4. Multilevel logistic regression for random effects related to optimal breastfeeding practice for mothers in selected West African Countries (empty model).

\begin{tabular}{l|c|c|c}
\hline & Guinea & Nigeria & Sierra Leone \\
\hline Parameter & Empty Model & Empty Model & Empty Model \\
\hline Random Effect & & & \\
\hline Community -level variance (SE) & $2.234(.77)$ & $0.836(.14)$ & $0.897(.14)$ \\
\hline ICC $(\%)$ & 40.4 & 20.3 & 21.4 \\
\hline Log-likelihood & -575.4 & -3398.4 & -1958.3 \\
\hline Model Fitness & & & \\
\hline Log-likelihood test & $55.9^{* * *}$ & $150.87^{* * *}$ & $157.7^{* * *}$ \\
\hline AIC & 1156.7 & 6802.8 & 3922.6 \\
\hline
\end{tabular}

Note: ${ }^{* *} \mathrm{p}<0.05, \mathrm{p}>0.05$ (not significant).

Table-5. Multilevel logistic regression for random effects related to optimal breastfeeding practice for mothers in selected West African Countries (Model 1,2,3).

\begin{tabular}{|c|c|c|c|c|c|c|c|c|c|}
\hline & \multicolumn{3}{|c|}{ Guinea } & \multicolumn{3}{|c|}{ Nigeria } & \multicolumn{3}{|c|}{ Sierra Leone } \\
\hline Parameter & $\begin{array}{c}\text { Model } \\
1 \\
\end{array}$ & $\begin{array}{c}\text { Model } \\
2 \\
\end{array}$ & $\begin{array}{c}\text { Model } \\
3 \\
\end{array}$ & $\begin{array}{c}\text { Model } \\
1 \\
\end{array}$ & $\begin{array}{c}\text { Model } \\
2 \\
\end{array}$ & $\begin{array}{c}\text { Model } \\
3 \\
\end{array}$ & $\begin{array}{c}\text { Model } \\
1 \\
\end{array}$ & $\begin{array}{c}\text { Model } \\
2 \\
\end{array}$ & $\begin{array}{c}\text { Model } \\
3 \\
\end{array}$ \\
\hline $\begin{array}{c}\text { Random } \\
\text { Effect }\end{array}$ & & & & & & & & & \\
\hline $\begin{array}{c}\text { Community } \\
\text {-level } \\
\text { variance } \\
(\mathrm{SE}) \\
\end{array}$ & $\begin{array}{l}1.047 \\
(.77)\end{array}$ & $\begin{array}{l}2.034 \\
(.72)\end{array}$ & $\begin{array}{l}2.217 \\
(.88)\end{array}$ & $\begin{array}{l}0.838 \\
(.17)\end{array}$ & $\begin{array}{l}0.737 \\
(.14)\end{array}$ & $\begin{array}{l}0.967 \\
(.20)\end{array}$ & $\begin{array}{l}0.858 \\
(.20)\end{array}$ & $\begin{array}{c}0.690 \\
(.12)\end{array}$ & $\begin{array}{l}0.861 \\
(.16)\end{array}$ \\
\hline $\operatorname{ICC}(\%)$ & 24.1 & 38.2 & 40.3 & 20.3 & 18.3 & 22.7 & 20.7 & 17.3 & 20.7 \\
\hline $\begin{array}{c}\text { Log- } \\
\text { likelihood }\end{array}$ & -279.2 & -571.8 & -491.3 & -3372.0 & -3381.6 & -2825.5 & -1002.3 & -1935.6 & -1546.5 \\
\hline $\begin{array}{c}\text { Model } \\
\text { Fitness }\end{array}$ & & & & & & & & & \\
\hline $\begin{array}{c}\text { Log- } \\
\text { likelihood } \\
\text { test }\end{array}$ & 5.05 & $48.9^{* *}$ & $44.6^{* *}$ & $138.9^{* *}$ & $123.1^{\text {*** }}$ & $127.7^{* * *}$ & $49.8^{* * *}$ & $106.1^{* * *}$ & $95.5^{* *}$ \\
\hline $\mathrm{AIC}$ & 588.5 & 1169.6 & 1020.6 & 6674.1 & 6791.1 & 5673.0 & 2034.6 & 3899.2 & 3135.1 \\
\hline
\end{tabular}

Note: ${ }^{*} \mathrm{p}<0.05, \mathrm{p}>0.05$ (not significant).

Breastfeeding practices in selected West African countries

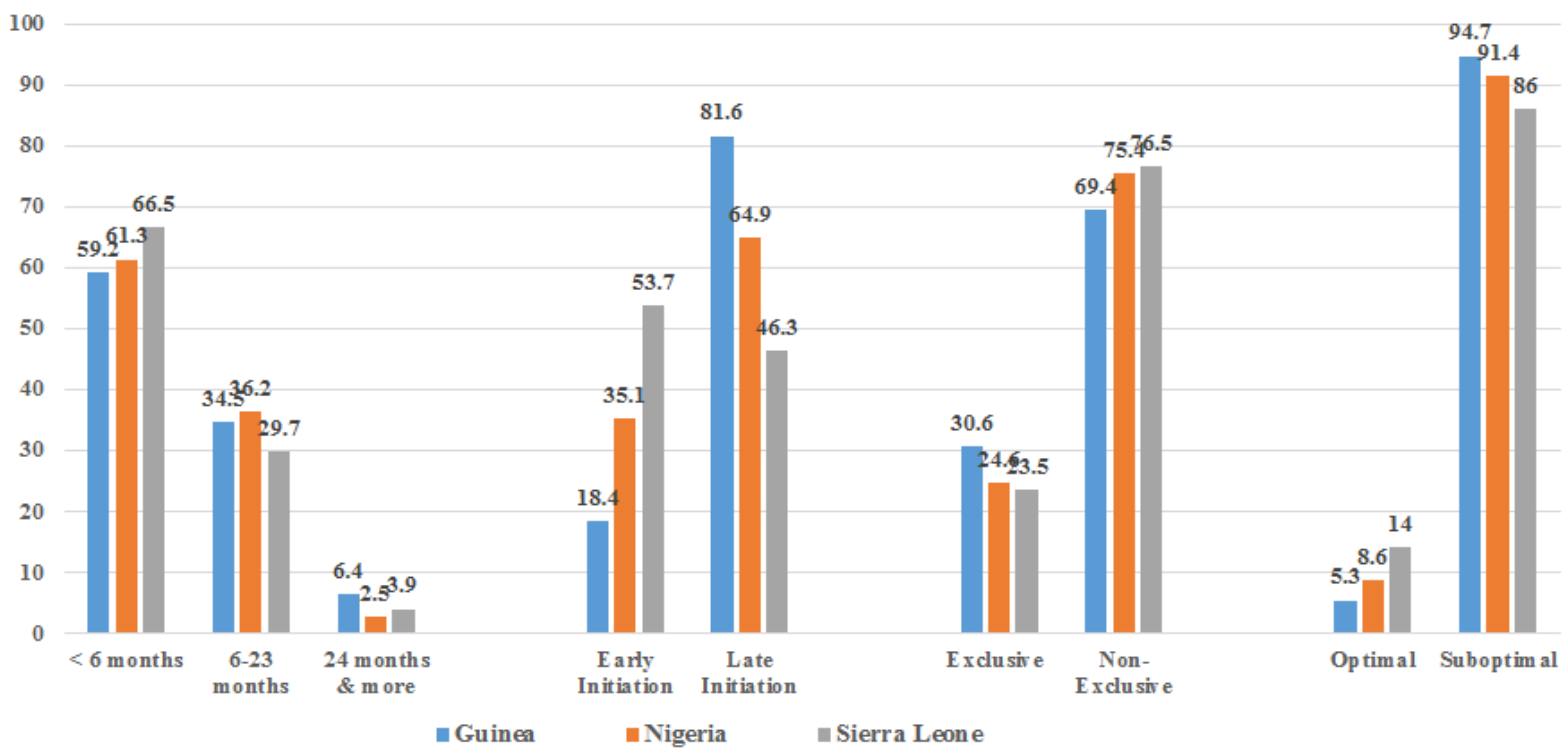

Figure-1. Percentage distribution of respondents by patterns of breastfeeding practices.

\section{Discussion}

This study addressed contextual factors that influenced patterns and practice of breastfeeding among mothers in Guinea, Nigeria and Sierra Leone as a representation of the acts among mothers in the West African region. Our noted that the prevailing patterns of breastfeeding among mothers in the study locations were not only restricted to individual-level factors but also community-level and household factors. Findings 
from our study on patterns of breastfeeding clearly showed that a larger number of mothers in the three countries fed introduced complementary breastfeeding before their infants were 6 months old. In Guinea for example, less than one-third of the mothers exclusively breastfed their infants for a duration of at least 6 months. The situation was not different among mothers in Nigeria and Sierra Leone. We discovered that that more than one-third of mothers in these countries failed to exclusively breastfeed their infants for a period of 6 months as recommended. Thus, our findings are indications that many infants in West Africa are not properly breastfed as long as exclusive breastfeeding is concern. Our findings are in corroboration with Horii et al. (2017); Oluwole, Agboola, Onyibe, and Adeyoju (2016); Sholaye et al. (2014); Bankole and Adetutu (2015) and UNICEF (2016) who empirically maintained that larger proportion of children born in Guinea, Nigeria and Sierra Leone were not exclusively breastfed as recommended by UNICEF/WHO.

More so, we noted in our study's findings that the timing of breastfeeding initiation among mothers was delayed beyond anticipated in the three countries while a significant number of mothers in these countries failed to adhere to the minimum recommended breastfeeding duration of 6 to 23 months. For instance, we discovered in our study that more than $60 \%$ of mothers across the three countries initiated breastfeeding late. In Nigeria, for instance about $65 \%$ of newly born babies had to wait for more than an hour before they were put to breastmilk. Our findings on patterns of breastfeeding are in line with Ogbo. et al. (2017) who observed that many babies born in Nigeria were denied breastmilk more than an hour after they were born. Similarly, Sika-Bright (2010) noted that a high number of newly born babies in Ghana were put to breastmilk earlier as expected. We also noted that our findings on timing of breastfeeding initiation among mothers in the selected West African countries for the study is a confirmatory of Abba, De Koninck, and Hamelin (2010) who noted that many mothers in Nigeria were not adhering to exclusive breastfeeding, and consequently making these children vulnerable to chronic and deadly childhood infections which are attributable to poor infant and young child feeding. Hence, findings from our study have empirically revealed that exclusive breastfeeding is rarely being practiced in the sub-region of West Africa. explicitly, adherence to exclusive breastfeeding for a duration of at least six months to many mothers in West Africa is still being regarded as a compulsion rather a necessity that are needful for mother and child healthy living. More so, the prevalence of mothers' adherence to optimal breastfeeding was found to be generally low across the three selected countries of this study. For instance, we noted that optimal breastfeeding was only practiced by about $6 \%, 9 \%$ and $14 \%$ of mothers in Guinea, Nigeria and Sierra Leone respectively. On the other hand, our findings could be explained in the context of Andy (2015) who through his extensive reviewed of empirical literature appraised the choice of breastfeeding among women in line with the health belief model.

One of our identified contextual factors influencing the choice of breastfeeding practices among mothers of reproductive age in this study is maternal factors at the individual level. We observed that age, age, level of educational attainment, religion affiliation, parity, marital status, employment status, micronutrient intake and body mass index had significance influence on mothers' adherence to optimal breastfeeding. For instance, we noted that from the unadjusted binary logistic regression results for Sierra Leone, age of mothers contributed significantly on their adherence to optimal breastfeeding. Occupation of women, and religion were also found our study to be significantly associated with optimal breastfeeding in Sierra Leone and Nigeria respectively. Our findings were in affirmation with Onah et al. (2014) in Nigeria and Fatoumata, Linda, Jean-Marie, and Marie-Pierre (2009) in Guinea where breastfeeding practices among women was not alienated to women's socio-demographic characteristics but also economic status. We also noted that our findings on individual factors as correlates of breastfeeding practice was not in isolation with Tampah-Naah and Kumi-Kyereme (2013) who posited that in Ghana, mothers intension to breastfeeding patterns was to a large extent dependent on age at birth, level of education, household wealth, literacy level of partners, place of residence and extent of healthcare facilities utilisation. Equally, our findings juxtaposed that by Horii et al. (2017); Mogre et al. (2016); Abba et al. (2010) and UNICEF (2016) where it was empirically and consistently maintained that poor socioeconomic status of women, inadequacy and absence of primary health facilities in many developing countries were healthcare facilities were crucial to mothers' non-adherence to proper and acceptable patterns of breastfeeding.

Another identified contextual correlates that influence breastfeeding practices among mothers in Guinea, Nigeria and Sierra Leone are household factors. We noted from the findings of our unadjusted binary logistic regression of the study that factors such as household wealth index and birth interval had direct and significant influence on adherence of mothers to optimal breastfeeding. For instance, household affluence or poverty, as well as interval between live births contributed significantly to whether a mothers would practice optimal breastfeeding or otherwise. Similarly, we discovered that household head, birth interval and poverty or wealth as the case may be had significant influence on adherence to optimal breastfeeding among mothers in Nigeria. In view with our findings from the binary logistic odds for fixed effects, we noted that the extent to which mothers in Guinea, Nigeria and Sierra Leone adhere to optimal breastfeeding was significantly influenced by household factors outlined in this study. Our findings were in agreement with Okolie (2012) and Ogunlesi (2010) who identified spouse level of education and household wealth index as some of the key predictors of breastfeeding practices among women.

Community-level factors are also one of the contextual factors in this study that influenced the breastfeeding practices in Guinea, Nigeria and Sierra Leone. We discovered from the unadjusted binary 
logistic regression results of our study that community type (rural or urban) significantly influenced decision of mothers towards choice of breastfeeding practices in the three selected countries. Also, was evident from our study's findings that community level of poverty, particularly among women remained a key predictor of the extent of women adherence to optimal breastfeeding across our study locations. Similarly, we noted that the extent to which optimal breastfeeding was practiced in all the three countries was largely attributable to the level of maternal education in the communities. Based on our findings, it is therefore, imperative that the prevalence of adherence to optimal breastfeeding by mothers in a community could be explained in the interactional effect between community level of maternal education and community level of maternal and child healthcare utilisation. In line with these, we noted that the decision to practice optimal breastfeeding by mothers in all the three countries in this study was significantly influenced by community level of antenatal care visits and place of child delivery. Our binary logistic ratio fixed effects results showed that the likelihood of women's adherence to optimal breastfeeding in Sierra Leone was strongly influenced by level of media saturation in the country.

Likewise, our findings were in agreement with World Health Organization (2017) and Andy (2015) who empirically maintained that the choice or possibility that a group of woman in a given community would adhere to the recommended infant and young child feeding could be explained in the context of the community level of maternal socioeconomic status and community level of accessibility and utilisation of primary healthcare facilities. More so, our findings were in line with Ukegbu, Ukegbu, Onyeonoro, and Ubajaka (2011) who noted in their empirical study that mothers living in rural communities of Anambra State, Southeast Nigeria breastfed their babies for a longer duration due to their conformity to traditional norms and values in their rural settlements. Also, in a similar study conducted in half a decade later five years later by Rees, Hawkesworth, Moore, Dondeh, and Unger (2016) it was argued that shortage and inaccessibility of primary healthcare facilities had negative influence on mothers' choice of breastfeeding practices among mothers in Gambia.

In view of all this, it is imperative that community factors play a significant role on the adherence of women to optimal breastfeeding practice or otherwise in the sub-region of West Africa. For instance, we noted that community-level characteristics accounted for $38.2 \%, 18.3 \%$ and $17.3 \%$ variation in adherence to optimal breastfeeding practice for mothers in Guinea, Nigeria and Sierra Leone respectively. Hence, mothers of reproductive age adherence to optimal breastfeeding in the sub-region goes beyond just an individual-level and household factors but also the community level characteristics of mothers.

\section{Conclusion}

The study described patterns of breastfeeding practices among mothers, and further revealed the fixed and random effects relating to optimal breastfeeding practices in the studied countries. Results revealed that suboptimal breastfeeding was widely practiced among mothers in all the three countries. Results for Nigeria showed that religion, employment status and occupation are predictors of breastfeeding practices among mothers at individual level. Unlike in Nigeria, marital status was a significant predictor of optimal population at individual level in Sierra Leone. Results across the studied countries revealed that household, individual and community-level factors significantly influenced breastfeeding among mothers. It is therefore imperative for further studies on breastfeeding to adopt both qualitative and quantitative methods in exploring cultural influence on breastfeeding, and in their attempt to establish the association between contextual factors and breastfeeding practices among mothers who are breastfeeding for the very first time.

\section{References}

Aakre, I., Lilleengen, M., Aarsand, M., Strand, T., Barikmo, I., \& Henjum, S. (2017). Infant feeding practices in the Saharawi refugee camps Algeria, a cross-sectional study among children from birth to six months of age. International Breastfeeding Journal, 8(12), 1-10. Available at: 10.1186/s13006-016-0098-1.

Abba, A. M., De Koninck, M., \& Hamelin, A. M. (2010). A qualitative study of the promotion of exclusive breastfeeding by health professionals in Niamey, Niger. International Breastfeeding Journal, 5(8), 4-7.

Akinwande, O. A., Dikko, H. G., \& Samson, A. (2015). Variance inflation factor: As a condition for the inclusion of suppressor variable(s) in regression analysis. Open Journal of Statistics, 5(7), 754-767. Available at: https://doi.org/10.4236/ojs.2015.57075.

Amah, C., K., Ekwe, O., C., Andrew, C. A., Ezeugwu, M. I., \& Orekyeh, E. S. (2015). What we hear and what we do? An analysis of the perceptual influence of child spacing campaigns on the knowledge, attitude and practices of rural women in South-East Nigeria. Journal of Biology, Agriculture and Healthcare, 5(14), 155-170.

Andy, E. (2015). A literature review of the factors that influence breastfeeding: An application of the health belief model. International Journal of Nursing and Health Science, 2(3), 28-36.

Arora, A., Manohar, N., Hayen, A., Bhole, S., Eastwood, J., Levy, S., \& Scott, J. (2017). Determinants of breastfeeding initiation among mothers in Sydney, Australia: Findings from a birth cohort study. International Breastfeeding Journal, 12(1), 39-39. Available at: https://doi.org/10.1186/s13006-017-0130-0.

Asfaw, M., Argaw, M., \& Kefene, K. (2015). Factors associated with exclusive breastfeeding practices in Debre Berhan District, Central Ethiopia: A cross sectional community based study. International Breastfeeding Journal, 1O(23), 19. Available at: 10.1186/s13006-015-0049-2. 
Bankole, O. T., \& Adetutu, O. (2015). Exclusive breastfeeding practice and infant survival Northern Nigeria. Journal of Demography \& Social Statistics, 2(1\&2), 28-36.

Bisiriyu, L. A., Bankole, T. O., \& Solanke, B. L. (2016). Maternal and child health care services utilization and infant survival in Northern Nigeria. Ife Journal of Behavioural Research 8(1 \& 2), 54-71.

Derso, T., Biks, G., Tariku, A., \& Tebeje, N. (2017). Correlates of early neonatal feeding ractice in Dabat HDSS site, Northwest Ethiopia. International Breastfeeding Journal, 12(1), 1-7. Available at: https://doi.org/10.1186/s 13006017-0116-y.

Diallo, F., Bell, L., Moutquin, J., \& Garant, M. (2009). The effects of exclusive versus non-exclusive breastfeeding on specific infant morbidities in Conakry. The Pan African Medical Journal, 2(2), 1-9. Available at: 10.4314/pamj.v2i1.51704.

Engebretsen, I., Nankabirwa, V., Doherty, T., \& Diallo, A. (2014). Early infant feeding practices in three African countries: The Promise-EBF trial promoting exclusive breastfeeding by peer counsellors. International Breastfeeding Journal, 9(19), 1-11. Available at: 10.1 186/1746-4358-9-19.

Fatoumata, B. D., Linda, B., Jean-Marie, M., \& Marie-Pierre, G. (2009). The effects of exclusive versus non-exclusive breastfeeding on specific infant morbidities in Conakry. The Pan African Medical Journal, 2(2), 1-9. Available at: 10.11604/pamj.2009.2.2.51.

Genetue, H., Yenit, M., \& Tariku, A. (2017). Breastfeeding counseling and support are associated with continuous exclusive breastfeeding from one week to six months of age among HIV exposed infants in north Gondar zone, Ethiopia: A cross-sectional study. International Breastfeeding Journal, 12(21), 1-8. Available at: 10.1186/s13006017-0113-1.

Hashim, T., Mgongo, M., Katanga, J., Uriyo, J., Damian, D., Stray-Pedersen, B., \& Msuya, S. (2017). Predictors of appropriate breastfeeding knowledge among pregnant women in Moshi Urban, Tanzania: A cross-sectional study. International Breastfeeding Journal, 12(11), 1-8. Available at: 10.1186/s13006-017-0102-4.

Horii, N., Allman, J., Martin-Prével, Y., \& Waltisperger, D. (2017). Determinants of early initiation of breastfeeding in rural Niger: Cross-sectional study of community based child healthcare promotion. International Breastfeeding Journal, 12(41), 1-10. Available at: https://doi.org/10.1186/s13006-017-0134-9.

Jakobsen, M. S., Sodemann, M., Biai, S., Nielsen, J., \& Aaby, P. (2008). Promotion of exclusive breastfeeding is not likely to be cost effective in West Africa: A randomized intervention study from Guinea-Bissau. Acta Paediatr Journal, $97(1), 68-75$.

Julie, J. O., Ene-Obong, H. N., Edet, E. E., \& Udoh, E. E. (2016). Association of maternal nutrition knowledge and child feeding practices with nutritional status of children in Calabar South Local Government Area, Cross River State. Nigeria. International Journal of Home Science, 2(1), 293-298.

McLeroy, K. R., Bibeau, D., Steckler, A., \& Glanz, K. (1988). An ecological perspective on health promotion programs. Health Education Quarterly, 15(4), 351-377. Available at: https://doi.org/10.1177/109019818801500401.

Merlo, J., Wagner, P., Ghith, N., \& Leckie, G. (2016). An original stepwise multilevel logistic regression analysis of discriminatory accuracy: The case of neighbourhoods and health. PLoS One, 11(4), e0153778. Available at: https://doi.org/10.1371/journal.pone.0153778.

Mogre, V., Dery, M., \& Gaa, P. (2016). Knowledge, attitudes and determinants of exclusive breastfeeding practice among Ghanaian rural lactating mothers. International Breastfeeding Journal, 11(12), 1-8. Available at: 10.1186/s13006016-0071-Z.

Morhason-Bello, I. O., Adedokun, B. O., \& Ojengbede, O. A. (2009). Social support during childbirth as a catalyst for early breastfeeding initiation for first-time Nigerian mothers. International Breastfeeding Journal, 4(1), 1-7. Available at: https://doi.org/10.1186/1746-4358-4-16.

Mucha, N., Blomberg, J. H., \& Stockdale, K. (2016). Nutrition landscape analysis for 14 countries. Geneva, Switzerland: Global Alliance for Improved Nutrition (GAIN).

O'brien, R. M. (2007). Quality \& Quantity. A Caution Regarding Rules of Thumb for Variance Inflation Factors, 41(5), 673-690.

Ogbo, F., Page, A., Idoko, J., Claudio, F., \& Agho, K. (2017). Have policy responses in Nigeria resulted in improvements in infant and young child feeding practices in Nigeria? International Breastfeeding Journal, 12, 19.

Ogbo., F., Page, A., Idoko, J., Claudio, F., \& Agho, K. (2017). Have policy responses in Nigeria resulted in improvements in infant and young child feeding practices in Nigeria? International Breastfeeding Journal, 12(19), 1-10. Available at: 10.1186/s13006-017-0101-5.

Ogunlesi, T. (2010). Maternal socio-demographic factors influencing the initiation \& exclusive breastfeeding in a Nigerian semi-urban setting. Maternal Child Health Journal, 14(3), 459-465. Available at: https://doi.org/10.1007/s 10995008-0440-3.

Okolie, U. (2012). Problems encountered by breastfeeding mothers in their practice of exclusive breast feeding in tertiary hospitals in Enugu State, South-East Nigeria. International Journal of Nutrition and Metabolism, 4(8), $107-113$.

Oluwole, B., Agboola, A., Onyibe, J., \& Adeyoju, A. (2016). Improving maternal nutrition in Nigeria: A review. International Research Journal of Agricultural and Food Sciences, 1(2), 17-22.

Onah, S., Osuorah, D., Ebenebe, J., Ezechukwu, C., Ekwochi, U., \& Ndukwu, I. (2014). Infant feeding practices and maternal socio-demographic factors that influence practice of exclusive breastfeeding among mothers in Nnewi South-East Nigeria: A cross-sectional and analytical study. International Breastfeeding Journal, 9(6), 1-10.

Otoo, G. E., Lartey, A. A., \& Pérez-Escamilla, R. (2009). Perceived incentives and barriers to exclusive breastfeeding among periurban Ghanaian women. Journal of Human Lactation, 25(1), 34-41. Available at: https://doi.org/10.1177/0890334408325072.

Population Reference Bureaus (PRB). (2018). World population data sheet with a special focus on changing age structure.

Rees, C. P., Hawkesworth, S., Moore, S. E., Dondeh, B. L., \& Unger, S. A. (2016). Factors affecting access to healthcare: An observational study of children under 5 years of age presenting to a rural Gambian primary healthcare centre. PLoS One, 11(6), e0157790. Available at: 10.1371/journal.pone.0157790. 
Rutstein, S., \& Rebecca, W. (2014). The effects of fertility behavior on child survival and child nutritional status: Evidence from the demographic and health surveys, 2006 to 2012. DHS Analytical Studies, No. 37. ICF International Rockville, Maryland.

Sholaye, O., Badejo, C., \& Jeminusi, O. (2014). Dietary habits of pregnant women in Ogun-East Senatorial Zone, Ogun State Nigeria: A comparative study. International Journal of Nutrition and Metabolism, 6(4), 42-49. Available at: https://doi.org/10.5897/ijnam2014.0170.

Sika-Bright, S. (2010). Socio-cultural factors influencing infant feeding practices of mothers attending welfare clinic in Cape Coast, Ghana: Department of Sociology and Anthropology, University of Cape Coast. Retrieved from: http://www.ifra-nigeria.org/IMG/pdf/Sika.pdf. [Accessed 15 October 2019].

StataCorp. (2015). Stata statistical software: Release 14. College Station, TX: StataCorp LP.

Tampah-Naah, A. M., \& Kumi-Kyereme, A. (2013). Determinants of exclusive breastfeeding among mothers in Ghana: A cross sectional study. International Breastfeeding Journal, 8(13), 1-7. Available at: 10.1186/s 13006-017-0103-3.

Tewabe, T., Mandesh, A., Gualu, T., Alem, G., Mekuria, G., \& Zeleke, H. (2017). Exclusive breastfeeding practice and associated factors among mothers in Motta town, East Gojjam zone, Amhara Regional State, Ethiopia, 2015: A cross-sectional study. International Breastfeeding Journal, 12, 12.

Ukegbu, A., Ukegbu, P., Onyeonoro, U., \& Ubajaka, C. (2011). Determinants of breastfeeding patterns among mothers in Anambra State, Nigeria. South African Journal of Child Health, 5(4), 112-116.

UNICEF. (2016). Infant and young child feeding: Global database. Retrieved from: https://data.unicef.org/topic/nutrition/infant-and-young-child-feeding. [Accessed 26/05/ 2019].

UNICEF. (2017). World Breastfeeding Trends Initiative [online database]. Delhi: IBFAN Asia.

UNICEF Global Databases. (2014). Based on DHS, MICS, and other national surveys; UNICEF, World Bank, WHO Joint Malnutrition Estimates, 2013. Retrieved from: http://data.unicef.org/child-mortality/underfive\#sthash.V2It9JL4.dpuf. [Accessed 23 October, 2018].

Victora, C. G., Bahl, R., Barros, A. J., França, G. V., Horton, S., Krasevec, J., \& Rollins, N. C. (2016). Breastfeeding in the 21st century: Epidemiology, mechanisms, and lifelong effect. The Lancet, 387(10017), 475-490. Available at: https://doi.org/10.1016/s0140-6736(15)01024-7.

World Health Organization. (2016). Infant and young child feeding model chapter for textbook for medical student and allied health professionals. from: http://www.who.int/maternal child adolescent/documents/9789241597494/en. [Accessed 26/05/2019]

World Health Organization. (2017). Global targets 2025. To improve maternal, infant and young child nutrition. Retrieved from: www.who.int/nutrition/topics/nutrition_globaltargets2025/en/. [Accessed 26/05/2019]. 